\title{
The Creation of a Program of Engagement and Outreach for COVID-19 Among African Americans Through Community-Academic Partnerships
}

\author{
Marla B. Hall ${ }^{1}$. Nancy L. Winterbauer ${ }^{1} \cdot$ Courtney Klinger $^{1} \cdot$ Mary Tucker-McLaughlin $^{2} \cdot$ Ann Rafferty $^{1}$. \\ Gwendolyn Greene $^{3}$. Savannah Dodson ${ }^{1}$
}

Accepted: 25 May 2021 / Published online: 31 May 2021

(c) The Author(s), under exclusive licence to Springer Science+Business Media, LLC, part of Springer Nature 2021

\begin{abstract}
The COVID-19 pandemic has disproportionately affected racial and ethnic minority groups in the U.S. Over a 7-week period in late 2020, with funding from the NC Office of Minority Health and Health Disparities, the West Greenville Health Council (WGHC), a community-academic, non-profit partnership, engaged and activated a 27-member organizational partnership network for COVID-19 health communication and personal protective equipment (PPE) distribution in African American communities in Eastern North Carolina. Outreach included: local production and dissemination of 10 culturally relevant safety videos, 10 risk, prevention, and safety postcard messages, 3 virtual forums, and PPE kit distribution via the network and their distribution venues. Communication mediums included social media posts (i.e., Facebook and YouTube), network email distribution lists, and postcards distributed along with PPE kits. Outreach activities were evaluated via an online survey, reach of social media posts, and PPE distribution. Working through the organizational network, the WGHC reached a combined total of 30,310 community members with educational materials. Forty-four outreach events were held during this period and over 8000 PPE kits were distributed. The online survey, distributed through the network, yielded more than 400 completed questionnaires. This tool was used to gain insights on community perceptions of COVID-19 safety barriers and media messages. The activation of the network as an approach for rapid response to an emerging public health crisis greatly expanded the reach of the WGHC. The WGHC is working to institutionalize the network to address future emerging health threats, as well as the dissemination of health information more generally.
\end{abstract}

Keywords Rural $\cdot$ African american $\cdot$ COVID-19 $\cdot$ Community partnerships

\section{Introduction}

As documented extensively in the literature, due to systemic oppression and risk behavior engagement, African Americans (AAs) experience a multitude of health disparities which impact their health outcomes and subsequent quality of life [1, 2]. In addition, when rurality is coupled with race/ ethnicity, challenges are further exacerbated. Although there

Marla B. Hall

Hallmar114@ecu.edu

1 Brody School of Medicine, East Carolina University, Greenville, NC, USA

2 School of Communication, East Carolina University, Greenville, NC, USA

3 West Greenville Health Council, Greenville, NC, USA is a need to develop health promotion programs and interventions specifically for rural AA, recruitment and retention for such programs have proven difficult $[3,4]$. The identified barriers include attitudes of medical mistrust, lack of cultural relevance or benefit to the individual or community, and social and economic factors which limit their ability to participate [4-6]. Unfortunately, the COVID-19 pandemic has accentuated many of these obstacles and resulting health inequities among AAs [7-9].

Therefore, in these unusual times, maximizing AA engagement and outreach through community partnerships is a vital approach to circumvent these challenges $[2,6,10]$. Specifically, a multifaceted community partnership is key to ensuring that engagement and outreach deliverables are acquired as intended to improve health conditions within the population $[11,12]$. AA community partnerships have been noted as beneficial because of their ability to build 
upon the existing strengths and resources of the community, thus cultivating trust among community members and health professionals and researchers $[12,13]$. This strategy aids in strengthening community buy-in, as well as participant recruitment and behavior adoption $[2,14,15]$.

Moreover, the COVID-19 pandemic has highlighted that mobilizing community partnerships is essential to rapid response efforts for education dissemination and personal protective equipment (PPE) distribution to increase uptake of preventive measures [16-18]. Since rural AAs are at higher risk of COVID-19 hospitalization and death, as a consequence of pre-existing conditions and social and structural determinants, these tasks are imperative within this vulnerable community $[17,19,20]$. Hence, the purpose of this paper is to describe rapid response community partnership mobilization activities to reduce COVID-19 disparities among the demographic. Furthermore, lessons learned will be discussed to offer insights to effectively expand reach within and engage with this unique population.

\section{Methods}

\section{West Greenville Health Council}

Over its 4-year history, the West Greenville Health Council (WGHC) has focused activities in West Greenville, an historically and predominantly AA, socially, and economically depressed community in Pitt County, North Carolina (NC). The WGHC, a community-academic partnership, supports the work of concerned citizens to prioritize local health issues, identify their social determinants, and ameliorate health inequities through multisectoral partnerships. The Council also employs a collaborative, community-driven participatory public health approach for health improvement and to overcome barriers that prevent residents from experiencing their best quality of life.

Staying true to its mission, the WGHC applied for and received rapid 7-week funding from the NC Office for Minority Health and Health Disparities. This funding was implemented to build awareness and support among AAs for COVID-19 prevention, testing, contact tracing, and isolation support initiatives across Pitt County. WGHC members are long-time residents of the city of Greenville with social networks extending deeply into the AA community throughout the county. Consequently, this made the identification and recruitment of external community organizations for COVID-19 engagement and outreach partnership easily attainable.

\section{Key Informants}

WGHC relied heavily on key informants to expand and diversify its reach for obtaining additional partnerships. As noted in the literature, the inclusion of key informants is important for recruitment endeavors. Due to their social and professional positions in the community, they possess a wealth of knowledge related to community perspectives [21]. These individuals are laboriously embedded and active within their communities as well, often acting as gatekeepers [22]. The goal of this methodology was to promote diversification of recruited partner entities.

\section{Outreach Activities}

The outreach effort included: (1) the local production and dissemination of culturally relevant safety videos, (2) risk, prevention, and safety postcard messages, and (3) three COVID-19 virtual forums with local and state experts, as well as formal and informal community leaders. Communication vehicles included social media posts (i.e., Facebook and YouTube), postcards, and network email distribution lists. Outreach activities were evaluated via an online survey, reach of social media posts, and amount of PPE distributed.

\section{Memorandum of Understanding Agreements}

Upon successful recruitment of partner organizations, consent was procured. Within this task, memorandum of understanding (MOU) agreements were set forth to facilitate bilateral communication. The agreement was used to concretely outline the rights, roles, and responsibilities for all involved parties. The intent of this action was to augment favorable COVID-19 education dissemination and PPE distribution deliverables.

\section{Partner Stipends}

Consistent with a public health participatory approach to community engagement and to acknowledge the additional effort provided by the partners to support this work, each agency was awarded a stipend of between $\$ 250$ and $\$ 2000$ (dependent on level of effort and size of participating organization). 
Table 1 Organizational characteristics and deliverables

\begin{tabular}{|c|c|c|c|}
\hline Organization & $\mathrm{n}(\%)$ & Characteristics & Deliverables $^{\mathrm{a}}$ \\
\hline Faith-based organizations (FBOs) & $11(40.7 \%)$ & $\begin{array}{l}\text { Large }(>2500 \text { members) to small }(\sim 50 \\
\text { members) congregations } \\
\text { In-town and rural facilities } \\
\text { With and without health ministries }\end{array}$ & $\begin{array}{l}\text { Livestreamed project videos seven times } \\
\text { Distributed } 200 \text { print media via listserv } \\
\text { Shared WGHC social media posts } 16 \text { times } \\
\text { Co-sponsored COVID Panel Forum } \\
\text { Hosted at least one outreach event } \\
\text { Distributed } 500 \text { PPE } \\
\text { Collected } 20 \text { paper questionnaires }\end{array}$ \\
\hline Community-based organizations (CBOs) & $14(51.9 \%)$ & $\begin{array}{l}\text { Local and regional sororities } \\
\text { Local alliances } \\
\text { Charitable feeding organizations, } \\
\text { Step groups } \\
\text { Local libraries } \\
\text { Youth-serving agencies and leagues } \\
\text { HBCU associations } \\
\text { Local TV station } \\
\text { Intergenerational community-based group } \\
\text { Local health department }\end{array}$ & $\begin{array}{l}\text { Distributed } 130 \text { print media via listserv } \\
\text { Shared WGHC social media posts } \\
\text { Co-sponsored COVID Panel Forum } \\
\text { Distributed } 100 \text { PPE kits } \\
\text { Collected } 20 \text { paper questionnaires }\end{array}$ \\
\hline $\begin{array}{l}\text { Public housing and homeless serving } \\
\text { (PHHS) }\end{array}$ & $2(7.4 \%)$ & $\begin{array}{l}\text { Homeless shelter ( } 98 \text { individual bed } \\
\text { capacity and } 4 \text { family rooms) } \\
\text { Local housing authority ( } 720 \text { individual } \\
\text { units) }\end{array}$ & $\begin{array}{l}\text { Distributed } 100 \text { print media via listserv } \\
\text { Hosted at least two outreach events } \\
\text { Distributed } 1000 \text { PPE kits } \\
\text { Collected } 40 \text { paper questionnaires }\end{array}$ \\
\hline
\end{tabular}

${ }^{\text {a }}$ Signifies average deliverables per organizational category

\section{Results}

\section{Partner Organization Characteristics}

Recruitment efforts resulted in a total of 27 partner organizations, as illustrated in Table 1. These entities were stratified in three categories: (1) faith-based organizations (FBOs), (2) community-based organizations (CBOs), and (3) public housing and homeless serving (PHHS) agencies. Among the eleven FBOs, congregation sizes ranged from 50 to 2500 members, with some having established health ministries. In addition, locations were both in-town and in rural zones (see Table 1).

Regarding the 14 CBOs, these encompassed a variety of organizations within several settings. Namely, but not limited to, sororities, community centers, youth-serving agencies, and local alliances. Pitt County Health Department was also recruited for education and outreach activities. Moreover, intergenerational and charitable feeding organizations were successfully engaged in initiative delivery.

Finally, PHHS agencies played a vital role in program implementation. This organization category was comprised of a homeless shelter and the local housing authority. Among these two organizations, and as indicated in Table 1, WGHC was able to extend their reach to over 800 low-income and housing insecure individuals. As a result, much needed PPE was distributed to these vulnerable populations.

\section{Partnership Successes}

Working through the organizational network, the WGHC reached a combined total of 30,310 community members with COVID-19 educational materials over a 7 -week period. Forty-four outreach events were held during this time and over 8000 PPE kits were distributed. An online survey, also distributed through the network, yielded more than 400 completed questionnaires. This tool was used to gain insights on community perceptions of COVID-19 safety barriers and media messages.

There are notable strengths regarding the community partnership recruitment activities of this program as well. Specifically, WGHC was able to rapidly mobilize resources through membership and key informants to recruit an assortment of community partners who serve diverse members of the local AA community. These partners, along with their outreach partners, then constituted $>27$ sites for education dissemination and PPE distribution. Moreover, because these organizations and agencies have existing scheduled activities, WGHC deployed these as venues for COVID19 focused outreach. Additionally, by utilizing community members for recruitment, partners were more receptive of the program objectives and inclined to participate. Lastly, the development and utilization of a detailed MOU, in alignment with partners' capabilities, assisted the partners in remaining engaged and attentive of the deliverables. 


\section{Partnership Challenges}

However, there were challenges experienced as well. Specific to the MOU, a lack of understanding among community partners was evident and resulted in some agreements not being completed in a timely manner or at all. The factors of this outcome included the partners not being accustomed to engaged partnerships and the concept of resource sharing. This interpretation was also noted in reference to the completion of funder required reporting requirements to account for materials dissemination, which resulted in incomplete or absent documentation. Attributable to the pandemic, communication was overwhelmingly limited to virtual interaction (i.e., by phone, email and Zoom). The absence of the ideal face-to-face interaction resulted in instances of slow responsiveness from partners.

\section{Discussion}

The results of this rapid community partnership mobilization endeavor highlighted the importance of recruiting a variety of partners to expand and diversify reach among the AA population. Specifically, the FBOs, CBOs, and PHHS agencies were the focal point of the project. These organizations had the ability to integrate their knowledge of the local culture to maximize outreach efforts [23]. As a result, this eliminated the barrier of lack of trust that vulnerable populations have expressed concerning health research participation $[15,16,23]$.

Also noteworthy are the challenges experienced involving the necessity of virtual communication among community partners during the COVID-19 pandemic. Open communication and routine interaction among partners have been identified as a strategy to facilitate transparency of project logistics and expectations [24, 25]. Consequently, the reduced face-to-face contact in the community impacted the intimacy that meaningful partnership-building and sustainability requires. Therefore, approaches must be proactively explored in the future to maintain engagement [26]. Methods include scheduling monthly asynchronous group and bi-weekly individual partnership meetings prior to outreach, to be convened throughout the entire timeline of the project.

Furthermore, the participatory action research employed within this project is an advantageous approach to promote health equity among at-risk and marginalized populations [27]. One such element of that was the utilization of MOU agreements prior to outreach initiation, as well as resource sharing through the provision of stipends. These agreements are useful in describing partnership expectations in intelligible terms and providing partners with an explicit blueprint of the research process [28]. Subsequently, outreach transparency among all involved parties was fostered.
However, obtaining signed MOUs was not devoid of challenges. Appropriately, steps must be taken in the future to enhance compliance. In particular, the research team needs to continuously engage with and prime the partners throughout the year to facilitate rapid mobilization if funding opportunities arise. This includes educating the organizations to boost their comprehension and knowledge of MOU agreements. Educational services should also be provided specific to invoice completion and other funder-required administrative obligations.

\section{Conclusion}

Engaging and activating an organizational partnership network greatly extended the capacity of the WGHC to respond rapidly to the COVID-19 pandemic. Many of the limitations that were experienced occurred because of the emergent nature of the pandemic and the communication challenges imposed by it (i.e. no face-to-face meetings). As these restrictions are lifted, the WGHC is working to institutionalize the network. These efforts will be used to not only respond to emerging public health threats, but also for the distribution of health information more generally.

Funding This study was funded by the NC Office of Minority Health and Health Disparities (no grant number provided).

\section{Declarations}

Conflict of interest The authors declare that they have no conflict of interest.

\section{References}

1. Bailey, Z. D., Krieger, N., Agénor, M., Graves, J., Linos, N., \& Bassett, M. T. (2017). Structural racism and health inequities in the USA: Evidence and interventions. The Lancet (London, England), 389(10077), 1453-1463.

2. Hall, M. B., Eden, T. M., Bess, J. J., et al. (2017). Rural shopbased health program planning: A formative research approach among owners. Journal of Racial and Ethnic Health Disparities, 4(3), 507-514.

3. Diaz, V. A., Mainous, A. G., 3rd., McCall, A. A., \& Geesey, M. E. (2008). Factors affecting research participation in African American college students. Family Medicine, 40(1), 46-51.

4. Spence, C. T., \& Oltmanns, T. F. (2011). Recruitment of African American men: Overcoming challenges for an epidemiological study of personality and health. Cultural Diversity \& Ethnic Minority Psychology, 17(4), 377-380.

5. Byrd, G. S., Edwards, C. L., Kelkar, V. A., et al. (2011). Recruiting intergenerational African American males for biomedical research studies: A major research challenge. Journal of the National Medical Association, 103(6), 480-487.

6. Lang, R., Kelkar, V. A., Byrd, J. R., Edwards, C. L., PericakVance, M., \& Byrd, G. S. (2013). African American participation 
in health-related research studies: Indicators for effective recruitment. Journal of Public Health Management and Practice, 19(2), $110-118$.

7. Strickland, O. L., Powell-Young, Y., Reyes-Miranda, C., Alzaghari, O., \& Giger, J. N. (2020). African-Americans have a higher propensity for death from COVID-19: Rationale and causation. Journal of National Black Nurses' Association, 31(1), 1-12.

8. Kim, S. J., \& Bostwick, W. (2020). Social vulnerability and racial inequality in COVID-19 deaths in Chicago. Health Education \& Behavior, 47(4), 509-513.

9. Gu, T., Mack, J. A., Salvatore, M., et al. (2020). Characteristics associated with racial/ethnic disparities in COVID-19 outcomes in an academic health care system. JAMA, 3(10), e2025197.

10. D'Alonzo, K. T. (2010). Getting started in CBPR: Lessons in building community partnerships for new researchers. Nursing Inquiry, 17(4), 282-288.

11. Haidar, A., Khoei, A., Alex, S. E., et al. (2021). Community-academic partnerships to promote health literacy and address social needs among low-income families during COVID-19. Journal of Nutrition Education and Behavior, 53(1), 75-78.

12. Parrill, R., \& Kennedy, B. R. (2011). Partnerships for health in the African American community: Moving toward communitybased participatory research. Journal of Cultural Diversity, 18(4), $150-154$.

13. De Marco, M., Kearney, W., Smith, T., Jones, C., Kearney-Powell, A., \& Ammerman, A. (2014). Growing partners: Building a community-academic partnership to address health disparities in rural North Carolina. Progress in Community Health Partnerships: Research, Education, and Action, 8(2), 181-186.

14. Taylor, H. A., Henderson, F., Abbasi, A., \& Clifford, G. (2018). Cardiovascular disease in African Americans: Innovative community engagement for research recruitment and impact. American Journal of Kidney Disease, 72(5 Suppl 1), S43-S46.

15. Flores, G., Walker, C., Lin, H., et al. (2017). An innovative methodological approach to building successful community partnerships for improving insurance coverage, health, and health care in high-risk communities. Progress in Community Health Partnerships: Research, Education, and Action, 11(2), 203-213.

16. DiGuiseppi, G., Corcoran, C., Cunningham, T., et al. (2021). Mobilizing a community-academic partnership to provide DIY handwashing stations to skid row residents during COVID-19. Health Promotion Practice, 22(1), 9-12.

17. Joseph, J. J., Glover, A., Olayiwola, J. N., et al. (2021). Mask up: Academic-community-government partnerships to advance public health during COVID-19. Population Health Management. https:// doi.org/10.1089/pop.2020.0305
18. Perry, J., McClure, N., Palmer, R., \& Neal, J. L. (2021). Utilizing academic-community partnerships with nursing students to improve hand hygiene in elementary students to reduce transmission of COVID-19. NASN School Nurse. https://doi.org/10.1177/ $1942602 X 20986958$

19. Cheng, K., Sun, Y., \& Monnat, S. M. (2020). COVID-19 death rates are higher in rural counties with larger shares of Blacks and Hispanics. The Journal of Rural Health, 36(4), 602-608.

20. Millett, G. A., Jones, A. T., Benkeser, D., et al. (2020). Assessing differential impacts of COVID-19 on Black communities. Annals of Epidemiology, 47, 37-44.

21. McKenna, S. A., \& Main, D. S. (2013). The role and influence of key informants in community-engaged research: A critical perspective. Action Research, 11(2), 113-124.

22. Feldman, S., Radermacher, H., Bird, S., Browning, C., \& Thomas, S. (2008). Challenges of recruitment and retention of older people from culturally diverse backgrounds in research. Ageing and Society, 28, 473-493.

23. Wieland, M. L., Njeru, J. W., Alahdab, F., Doubeni, C. A., \& Sia, I. G. (2021). Community-engaged approaches for minority recruitment into clinical research: A scoping review of the literature. Mayo Clinic Proceedings, 96(3), 733-743.

24. Williamson, H. J., Chief, C., Jiménez, D., et al. (2020). Voices of community partners: Perspectives gained from conversations of community-based participatory research experiences. International Journal of Environmental Research and Public Health, 17(14), 5245.

25. Springer, M. V., \& Skolarus, L. E. (2019). Community-based participatory research. Stroke, 50(3), e48-e50.

26. Rubinger, L., Gazendam, A., Ekhtiari, S., et al. (2020). Maximizing virtual meetings and conferences: A review of best practices. International Orthopaedics, 44(8), 1461-1466.

27. Munns, A., Toye, C., Hegney, D., Kickett, M., Marriott, R., \& Walker, R. (2017). Peer-led aboriginal parent support: Program development for vulnerable populations with participatory action research. Contemporary Nurse, 53(5), 558-575.

28. Ross, L. F., Loup, A., Nelson, R. M., et al. (2010). The challenges of collaboration for academic and community partners in a research partnership: Points to consider. Journal of Empirical Research on Human Research Ethics, 5(1), 19-31.

Publisher's Note Springer Nature remains neutral with regard to jurisdictional claims in published maps and institutional affiliations. 